\title{
From Design to Impact: A Phenomenological Study of HumanMOOC Participants' Learning and Implementation into Practice
}

\author{
Patrice Torcivia Prusko \\ Harvard Graduate School of Education \\ Heather Robinson and Whitney Kilgore \\ University of North Texas \\ Maha Al-Freih \\ Princess Nourah Bint Abdulrahman University
}

\begin{abstract}
The purpose of this research study is to shift the focus on Massive Open Online Course (MOOC) research by changing the narrative surrounding MOOC effectiveness from issues of course completion and certification to the impact of these courses on participants' actual practices. The "Humanizing Online Teaching and Learning" or HumanMOOC was offered four times with 2,614 participants overall and covered topics on the elements of the Community of Inquiry framework: social presence, teaching presence, and cognitive presence. Through phenomenological inquiry, literature review, demographics, and interviews, the researchers gathered and analyzed information from learners who completed the HumanMOOC. Three themes of the interviews that emerged from the coding analysis process are: learning journeyers, I think I can, and bringing it back to the classroom. The intention to participate and to overcome barriers and the increase in self-efficacy as a result of personal accomplishment, impacted the participants' will to implement what was learned into their teaching practice.
\end{abstract}

Keywords: community of inquiry, humanizing, online learning, online teaching, pedagogy, presence, MOOC, mentoring, self-efficacy

Torcivia Prusko, P., Robinson, H., Kilgore, W., \& Al-Freih, M. (2020). From design to impact: A phenomenological study of HumanMOOC participants' learning and implementation into practice. Online Learning, 24(2), 166-186. https://doi.org/10.24059/olj.v24i2.2003 


\section{From Design to Impact: A Phenomenological Study of HumanMOOC Participants' Learning and Implementation into Practice}

Since their inception in 2008, Massive Open Online Courses (MOOCs) have generated considerable interest in the educational research community. This interest stems from the potential that these courses offer in providing flexible, affordable, and on-demand options for learning and development in a time of instant connectivity and constant change. Despite this rise in interest and research output, there are some major blind spots within this field of research that require serious attention. Early research in this area focused on categorizations of MOOCs based on their technological and pedagogical underpinnings, with this focus moving later to issues related to learners' experiences and patterns of engagement within a MOOC (Olazabalaga, Garrido, \& Ruiz, 2016). However, this shift in focus did not extend beyond learners' experiences and engagement within a MOOC. Many researchers have pointed out the need to examine the impact these informal learning experiences have on participants' actual practices after they participate in a MOOC and how different design factors support or hinder the transfer of knowledge and experiences gained to real-life situations (Castaño, Maiz, \& Garay, 2015; Olazabalaga et al., 2016). Some studies suggest that learners do not use the knowledge they gain in MOOCs in their jobs and that improvements in MOOC design could help remedy this problem (Milligan \& Littlejohn, 2014).

Understanding what factors in $\mathrm{MOOC}$ design, pedagogy, and learning activities relate to the transfer of knowledge, by examining learners' experience after they leave a course, is an important and interesting area of study. The need to fill this gap in the literature becomes even more critical given the fast pace at which knowledge, technology tools, and job roles and responsibilities are changing - which means that traditional on-the-job professional development and training are no longer sufficient in addressing professionals' continuing need for learning and development (Littlejohn \& Milligan, 2015). Unfortunately, research in the area of informal learning is still relatively limited, especially within teachers' professional learning literature (Gijbels, Raemdonck, Vervecken, \& Van Herck, 2012; Jobe, Östlund, \& Svensson, 2014; Macià \& García, 2016; Manuti, Pastore, Scardigno, Giancaspro, \& Morciano, 2015; Tour, 2017).

The purpose of this study is to examine the effectiveness of a MOOC offered on the Canvas Open Network entitled "Humanizing Online Teaching and Learning" (HumanMOOC) by exploring the impact that this informal learning experience had on learners' teaching and learning practices after they participated in the MOOC. The HumanMOOC covered topics on the elements of the Community of Inquiry (CoI) framework: social presence, teaching presence, and cognitive presence (Garrison, Anderson, \& Archer, 2000). Our topics of inquiry were: In what ways has participating in the MOOC changed how participants perceive and enhance presence in their online courses? What factors (i.e., course design, personal, and institutional) supported or hindered the implementation of these changes in participants' actual practice?

\section{Review of Relevant Literature}

\section{The Changing Nature of Professional Learning and Development}

Advances in and widespread adoption of digital technologies and network-based services have transformed what we need and expect from professional development and learning. These new expectations are influenced not only by technological advances, but also by changes in the pace and nature of professional knowledge and skills as well as employees' and practitioners' 
expectations for continuous opportunities and support for learning and development (Brown, 2017; Deloitte Insights, 2018; Gijbels et al., 2012; Kukulska-Hulme, 2012; Littlejohn \& Milligan, 2015; Purvis, Rodger, \& Beckingham, 2016; Thacker, 2017). Deloitte's fifth annual Global Human Capital Trends survey and report (2018) defines the twenty-first-century career as a "series of developmental experiences, each offering a person the opportunity to acquire new skills, perspectives, and judgment" (p. 41). The rapid pace at which old skills need to be redeveloped and new skills acquired is unprecedented and the nature of skills that are needed and valued in today's workforce is changing. Human-centered skills such as cross-disciplinary thinking, leadership, communication, and problem-solving skills are becoming more critical for success and adaptability than pure technical competencies and know-how (Deloitte Insights, 2018). With higher education lagging in providing flexible options for the development of these skills, organizations are taking the lead in reinventing professional learning and development by providing employees with access to self-directed and individualized learning solutions that enable them to take charge of their learning and address their current professional needs as well as to develop the skills of the future. Dynamic and personalized solutions are made possible through the curation of not only internal but also external content, such as open resources and MOOCs via learning and knowledge-sharing networks (Deloitte Insights, 2018; O’Brien, 2018).

Researchers and practitioners in many fields are acknowledging the implications these socioeconomic and technological changes have on how to effectively engage individuals, including higher education faculty and staff, in professional development and learning activities, which can no longer be fulfilled using traditional forms of formal professional development such as standalone, face-to-face, and intermittent workshops and seminars (Eraut, 2011; Fontana, Milligan, Littlejohn, \& Margaryan, 2015; Gijbels et al., 2012; Manuti et al., 2015; Stewart, 2014; Tour, 2017). These changes and new demands have given rise to other forms and models of professional learning including online informal learning venues that are ongoing, affordable, focus on the development of a community of peers through the use of social media and in line with the realities of a technology-driven and networked world (Gast, Schildkamp, \& van der Veen, 2017; Jobe et al., 2014; Littlejohn \& Milligan, 2015; Stewart, 2014). Such informal online learning opportunities and environments using social media tools and applications allow educators to become more active and take charge of their path of learning by sharing knowledge and experiences, reflecting on their current practices, and connecting with peers and networks outside their respective institutions. In addition, it allows for in-time access to information and support as the need arises, which can be difficult to accomplish using traditional professional development methods (Kukulska-Hulme, 2012; Macià \& García, 2016). Further, by providing faculty with the opportunity to engage with and adapt different technologies and social media tools in their own professional learning, they not only develop the skills and strategies needed to take charge of their own ongoing learning and development, but also develop an understanding from a student's perspective of how to best utilize these tools in their own teaching and professional practices (Kukulska-Hulme, 2012; Purvis et al., 2016; Stewart, 2014).

\section{Faculty Informal Professional Learning and Development: Trends and Strategies}

Faculty development and learning remains a critical issue that has faced higher education institutions for the past few years (Brown, 2018). Advances in digital technologies and open access to online content and networks have brought forth many learning opportunities and affordances that were not previously possible. However, informal learning as a construct has not been clearly defined or critically examined in the literature. One of the difficulties in reaching a unified 
definition of informal professional learning is that it encompasses a wide range of activities that vary significantly in terms of timing, role of the trainer or instructor (if any), source, structure, and intention, which makes it a challenge to identify and explain (Eraut, 2000, 2011; Livingstone, 2001; Manuti et al., 2015; Schulz \& Roßnagel, 2010). For instance, informal learning can be selfinitiated and self-managed by the individual as a response to an existing or anticipated need or can occur unintentionally or incidentally as a byproduct of day-to-day work responsibilities (Eraut, 2011; Tour, 2017). These informal learning episodes can happen in structured informal activities, such as Twitter chats (Kilgore, 2016), or unstructured contexts such as interacting with and observing coworkers or dealing with work challenges (Eraut, 2011). Moreover, informal learning episodes can take the form of self-study or can exhibit strong social elements through engagement with others in discussions and problem-solving activities (Manuti et al., 2015). While the theoretical underpinnings of and differences between formal and informal learning are outside the scope of this study, mentioning this distinction does highlight the importance of informal learning experiences for professional learning and development purposes.

As a result of these technological advances and changes to workplace expectations, researchers and practitioners are beginning to examine and experiment with less formal and more innovative professional learning initiatives in an attempt to understand how best to support faculty as they engage in self-directed, social, and just-in-time learning. For instance, Kelly and Antonio (2016) examined teachers' use of large and open teacher groups on social networking sites such as Facebook to access informal online peer support and found evidence of teachers' pragmatic use of these open informal networks to connect with other teachers, socialize, and seek and provide practical advice about teaching and teaching practices (e.g., sharing resources and responding to one another's questions). Structured Twitter chats have also been used to connect geographically distributed educators and form open online communities in order to facilitate authentic and justin-time learning and support (Beckingham, Nerantzi, Reed, \& Walker, 2015; Kilgore, 2016). Using phenomenological research methods, Kilgore (2016) analyzed 46 U.S. state-level Twitter chats to evaluate their structure, underpinning pedagogy, and perceived value. Kilgore found that these Twitter chats allowed the formation of informal and collaborative online learning communities that extend beyond school walls, and beyond the Twitter chat itself in some cases. In these informal online communities, participants share different perspectives, engage in professional discourse, challenge each other's ideas, and connect with experts and peers based on their own needs and schedule - all things that are not easily accomplished with institutionally sponsored one-size-fits-all workshops and seminars.

\section{MOOCs for Informal Professional Learning and Development}

MOOCs have quickly evolved and adapted to market needs. Earlier MOOCs were offered as stand-alone courses that were open to anyone and everyone in the world, without a clear sense of who, how, or why individuals join and participate in MOOCs (Daniel, 2012; Shah, 2016a). However, as MOOC research progressed, so did our understanding of the different engagement patterns and purposes of MOOC learners. One major and recent trend concerns the packaging of these courses and how they are promoted to address the needs of well-identified subgroups of target audiences (Shah, 2016a, 2016b). A clear example of this is the shift toward more specialized MOOCs that specifically target the corporate sector (Johnson, 2017). One example is Coursera, which now offers Coursera for Business where organizations can handpick courses for their employees and track their progress through them. This trend, while in part motivated by monetary reasons (Cook, 2016; Shah, 2016b), arose in response to market demands. For instance, Radford, 
Coningham, and Horn (2015) found that more than two-thirds of learners who signed up for one or more of the 24 MOOCs offered by the University of Pennsylvania through Coursera were working professionals, and over half of the registrants signed up for their MOOCs to either develop specific skills for their current jobs or learn new skills to get a job. Similarly, Littlejohn, Hood, Milligan, and Mustain (2016) examined the goals and motivations of 362 participants in an Introduction to Data Science MOOC offered on the Coursera platform. The researchers found that learners' primary motivations for participating in the MOOC were relevance to work, professional development, to expand their skill set, and to support career development and advancement.

This shift in the MOOC landscape highlights major implications that cannot be overlooked from a design or research perspective: the audience these MOOCs are targeting. MOOCs, especially those offered through major MOOC platforms, seem to have made a decisive shift toward professional learners who are seeking credentials that are acknowledged by organizations by focusing on assessment of high-demand skills in business and technology (Cook, 2016). As a result of this shift toward professional learning and development, research focusing on the design and implementation of MOOCs that is in line with the needs and wants of working professionals is gaining momentum (Littlejohn \& Milligan, 2015). With that being said, most of these studies are descriptive in nature and focus on learners' experience within a MOOC, or on the potential that MOOCs offer as a professional development option for practitioners in addressing organizational and institutional goals and bottom line (Radford et al., 2015; Laurillard, 2016). Although there is a consensus among practitioners and researchers regarding the need to understand the effectiveness of these courses as informal professional learning options and their impact on working professionals' actual practices, this area of research remains a serious challenge (Jobe et al., 2014; Milligan \& Littlejohn, 2014; Sneddon, Barlow, Bradley, Brink, Chandy, \& Nathwani, 2018). This study is an attempt to fill this gap by understanding learners experience in translating what has been learned in one specific MOOC, the HumanMOOC, to their actual practices.

\section{Humanizing Online Teaching and Learning: The HumanMOOC}

The HumanMOOC was designed to create a space that supports the formation and development of a community with the goal of exploring and sharing ideas and thoughts regarding online learning and teaching, rather than one-way knowledge dissemination. Further, a dual-layer design was used to accommodate the needs and preferences of HumanMOOC participants while still supporting the development of an active community of learners (Kilgore \& Al-Freih, 2017)). The first layer was contained within the Canvas Learning Management System (LMS) and served as a private "members-only" sharing and learning space for those who were not comfortable having their thoughts and comments displayed on the open Web. The second layer of the course was built around principles of connectivism, and participants were encouraged to share their learning process and progress openly on the web (e.g., blogs, Twitter, and other tools they wanted to explore). In both layers, participants engaged in the same weekly activities and assignments; however, the way that learning occurred and how assignments were created and shared were different (see Figure 1). 


\section{How did you participate in the HumanMOOC?}

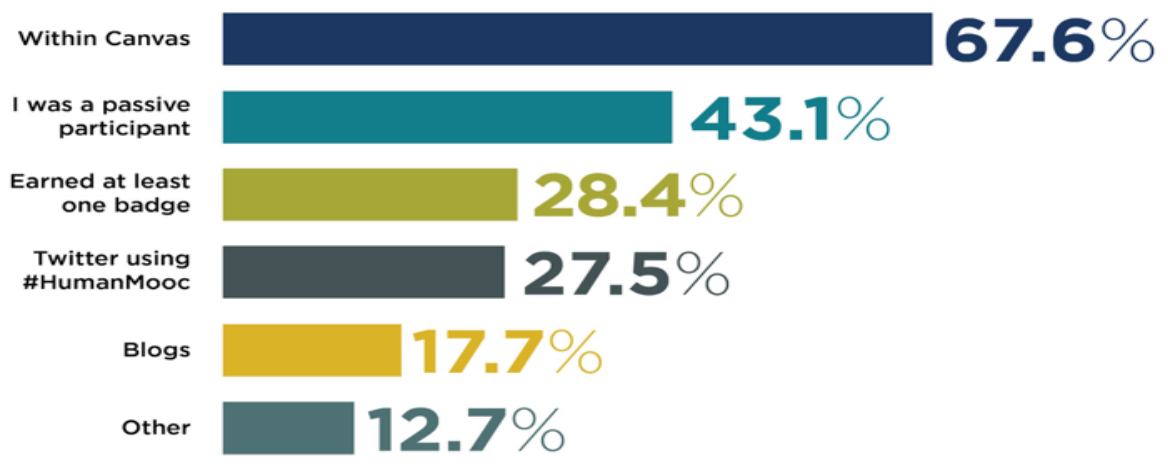

Figure 1. Participation patterns in the HumanMOOC.

The course consisted of three one-week modules covering the following topics: social presence, teaching presence, and cognitive presence. One major design consideration for the HumanMOOC was to ensure that its design was a direct translation of the principles of CoI. Thus, the course focused not only on covering topics related to CoI, but also on engaging participants in learning that allowed them the opportunity to experience what it feels and looks like to enhance presence in their own online courses. Participants had the option of earning single badges for completing the weekly assignment for the weekly topics (presences) they choose or earning a completion badge if they decide to complete all weekly assignments and badges in the MOOC. Instructional materials in the course included asynchronous discussions, expert interviews, synchronous discussions with experts, and scholarly articles. Graded assignments included:

- Creating and sharing an instructor introduction video and reflecting on the process of doing so in the discussion forum;

- Completing an assignment using VoiceThread, Flipgrid, or YellowDig, and reflecting on the experience in the discussion forum;

- Completing and reflecting on a triggering-events activity;

- Completing a peer review assignment in the discussion forum.

\section{Purpose of the Current Study}

Educators and professionals spend a considerable amount of time participating in and learning from informal professional learning activities and interactions (Eraut, 2011; Gijbels et al., 2012; Macià \& García, 2016). Despite this, educators' informal professional learning is understudied because of the wide range of informal and tacit experiences that contribute to faculty professional development and learning (e.g., discussion forums, Twitter chats, MOOCs, etc.), which adds to the difficulty of measuring its effectiveness or how it relates to the individual educators' actual practice (Boud \& Hager, 2012; Desimone, 2011; Macià \& García, 2016; Tour, 2017). Meaningful understanding of professional development and learning cannot be reached without understanding how it is translated into actual practice. Professional knowledge and skills 
acquired in professional development activities are not static, but rather subject to different interpretations by individuals that can only be understood through examination of their actual practices (Dall'Alba \& Sandberg, 2006). Hence, this study attempts to extend our understanding of MOOCs as professional learning and development venues by exploring participants' experiences after they have participated in a MOOC and the impact the MOOC learning experience had on their actual practices.

\section{Methods}

\section{Research Design}

A qualitative phenomenological study was conducted to explore how participants in the HumanMOOC perceived the phenomenon of implementing what they had learned, and its impact on their practices, after participation. Qualitative research is a naturalistic method that allows researchers to interpret and try to understand how participants experienced events they engaged in (Denzin \& Lincoln, 2005). The goal of phenomenological inquiry is to "obtain comprehensive descriptions that provide the basis for a reflective structural analysis that portrays the essences of the experience" (Moustakas, 1994, p. 13). Further, at the heart of phenomenology are the perspectives of individuals as the way to further understand a particular phenomenon (McConnellHenry, Chapman, \& Francis, 2009).

\section{Data Sources and Collection Processes}

Sources of data include literature review, demographics, and interviews. A survey was released to participants of the multiple iterations of the MOOC to deploy the initial demographic and those willing to be interviewed for the study volunteered after completing the questions. Onehour semi-structured interviews with open-ended questions were conducted with 10 participants to explore how participants in the MOOC learned and applied what they learned about using technology in support of learning goals and the CoI to enhance teaching, social and cognitive presence in their courses. Participants were asked about their intentions in taking the MOOC, their experience learning how to use new types of technology, and their experiences implementing what they learned in their practice. All interviews were conducted using Zoom, an online synchronous communication platform. These Zoom sessions were recorded and the audio transcribed and checked prior to coding for analysis.

\section{Data Analysis}

The first level of analysis from the participant interviews was aligned with the phenomenological approach for analysis (Moustakas, 1994). Researchers reviewed the transcripts and made note of important phrases and initial questions that might need further explanation. Next, transcripts were coded individually by researchers using in vivo methods, to honor the voice of each participant (Saldaña, 2009). Researchers met frequently during this process to discuss emerging codes and themes, and to address any questions that needed clarification. The next coding approach was used for theme development. Researchers entered the codes from the in vivo process from all researcher into NVivo, a data analysis software program. NVivo was used to assist in categorizing and consolidating the codes and to work toward theme development in a collaborative manner. 


\section{Validity}

We utilized multiple methods to establish validity, credibility, and trustworthiness to ensure the findings are "faithful to the participants' experience" (Ravitch \& Carl, 2015, p. 3924). To establish credibility researchers used member checking, peer debriefing, thick description of theoretical and methodological foundations, and triangulation. Three of the four researchers were wayfinders, or coaches who guide participants to meet their learning goals, of at least one iteration of the MOOC (Kilgore \& Lowenthal, 2015). Potential biases were discussed during whole-group meetings, as well as reflective exploration of past experiences that might shape interpretations. Investigator triangulation through collaborative research, multiple perspectives, peer coding, and debriefing were integrated to contribute to validity measures (Ravitch \& Carl, 2015).

All interview transcripts were anonymized prior to transcription. Names, locations, and other potentially identifying information were changed. Transcription was performed by a third party and verified by the interviewer and interviewee in preparation for coding using member checking. During data collection the researchers used purposeful sampling to gain different perspectives as a data triangulation approach. Further, perspective triangulation during data collection was used to make sure enough data was gathered to analyze. We continued to reach out to additional volunteers to obtain the depth and quality of information needed to answer our topic of inquiry (Ravitch \& Carl, 2015).

The four MOOC versions had the same foundation and activities, but with different participants each time there was variation in the experience and discussions brought to light. It was important to find participants who took different iterations of the MOOC. By looking at these different participant perspectives the researchers were seeking a holistic view of how the MOOC impacted participants' teaching practice in regard to the different presences.

\section{Results}

A total of 2,614 participants from around the world joined the HumanMOOC during one or more of its four iterations that ran from 2013 to 2017, with a team of four wayfinders that included faculty and instructional designers working on the design and iterations each time the course was run. A total of 102 completed responses to the survey were included in the final analysis. The sample included $62.7 \%$ females and $36.3 \%$ males. The majority of respondents were 30 or older (96\%) and held a master's or doctoral degree (85.3\%). Of those 102 respondents, $78.4 \%$ were full-time employees, $14.7 \%$ were part-time employees, $4 \%$ were not employed, and $2.9 \%$ were retired. Employment titles included college and university professors and lecturers, instructional and learning designers and technologists, program directors, project managers, and researchers. Participants were also asked about their previous experience with MOOCs, with an overwhelming majority indicating prior experience (97\%).

Because the researchers were interested in understanding the impact on practice as a result of participation in the MOOC, completing the MOOC was one criterion for inclusion in the interview pool. Hence, only participants who completed all weekly assignments and earned a HumanMOOC completion badge were recruited for this study. We defined completion as earning all badges in the course for recruiting participants. Those participants were invited to join the study with a recruiting message shared via the email list from the course registrations. The message explained the purpose of our study and that we would be recording interviews and asking them to 
fill out a survey. Participants were informed they would be asked for their permission to record the audio of their interviews and that pseudonyms would be used. We invited them to complete a survey containing demographic items and CoI questions, and asking if they would participate in a 45-minute to one-hour interview.

\section{Themes}

Based on the initial analysis of the transcripts, it was evident that to understand how and why participants changed their practices as a result of the MOOC, one must understand their initial intention and motivation for joining the MOOC. Consequently, the idea that the 10 learners of the HumanMOOC who participated in the semi-structured interviews were on a journey or path was compelling. Upon further analysis and following a consolidation process, three major themes emerged: learning journeyers, I think I can, and bringing it back to the classroom. We found a number of categories that cut across the two themes of I think I can and bringing it back to the classroom as depicted in Figure 2 which is further explained in the following theme discussion.

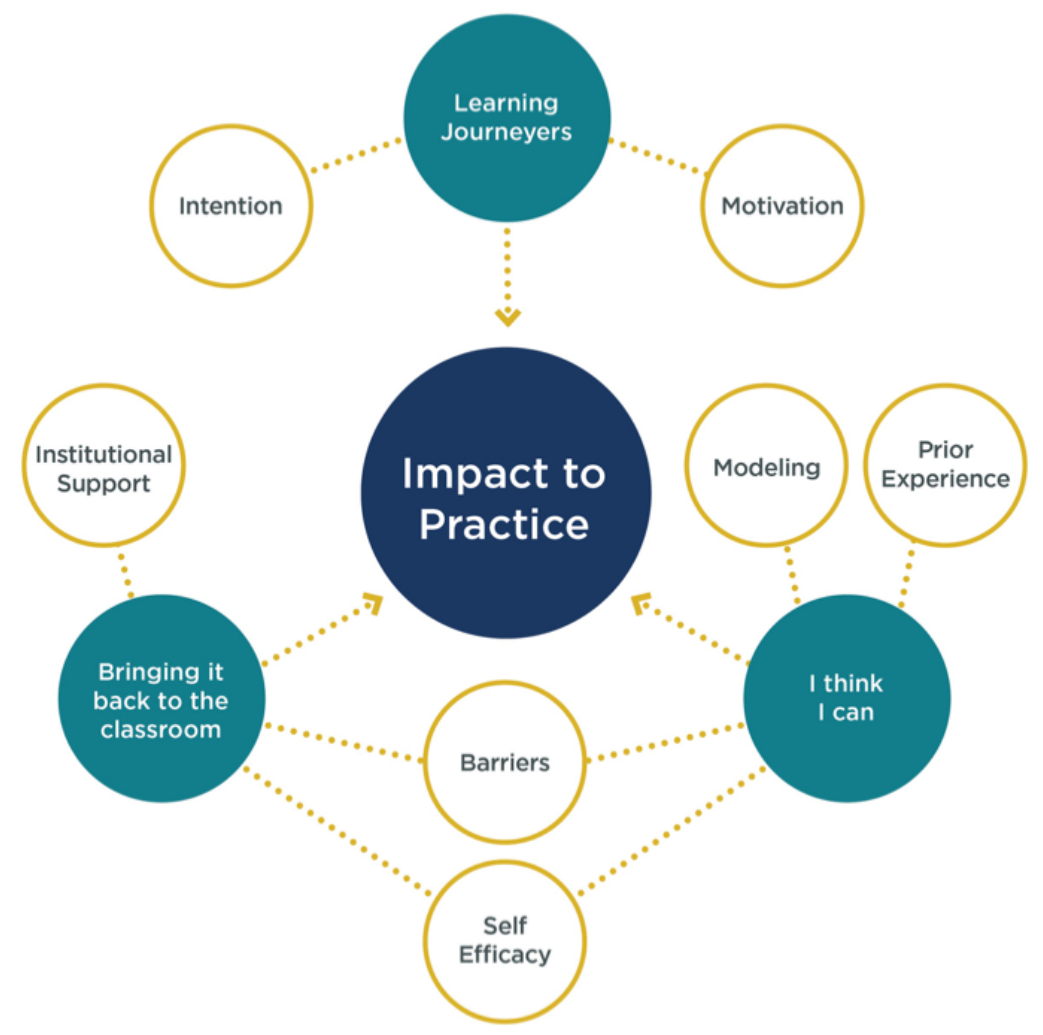

Figure 2. Categories and themes connected to learners' impact to practice

\section{Learning Journeyers}

The intention and motivation for participation, completion, earning badges, and engagement in MOOCs were connected to the theme of those we interviewed being on a journey or cycle of learning. All participants interviewed had clear, albeit different, intentions for joining the MOOC, and understanding their experience of implementing what was learned in the MOOC cannot be fully understood without careful consideration of their initial goals and intentions, and their individual learning. The intention to be a part of a learning community was a stronger thread 
than the intention to simply follow through with the course to completion. Julie explained this idea by stating "after so many different MOOCs that I attended, when I say that my intention is not usually to complete, it's because my intention is to learn other people's opinions." Eric said that the MOOC activities were a great way to build community and connections. He recalled a specific event when a leader in the social media community he follows led a Google Hangout and he connected with her:

It was really fun to see her live in the Google Hangouts, and actually for whatever reason, I got to be a part of it, that chat, which was great...to be able to ask some questions and just to put a face to a name and to a Twitter feed that I'd been following for a while and had connected through kind of more non-face-to-face experiences... again that just continued to solidify that sense of social presence that she was talking about in that setting.

The intention and motivation for a few others in taking the course was specifically to integrate learning in their classrooms or to learn new e-learning techniques. The use of the CoI model and the specific LMS used, Canvas, were important factors in some participants' learning. Julie explained that she joined the MOOC with the intention of participating in the discussion and learning from the conversations, not for completing assignments or completing the content. An important takeaway for Beth was understanding that

it's about who you're learning with, or, you know, and how people are engaging with each other that actually challenges you and makes your thinking bigger and makes you think about things in a different way than you have before. That was big part of the value that I got out of it, because I did go outside of my comfort zone.

Those interviewed had mixed feelings about the motivation of badges offered during the course. During the first iterations of the MOOC, badges were new and participants were either highly motivated to earn badges or not. Heidi stated, "I know badges motivate some people. They like to have their recognition public. It's not for me. My goal was really to look for new techniques." Missy, on the other hand, earned all the badges. "The badges at that point were kind of the icing on the cake or the caramel on the ice cream. It was the topping that kind of enticed it and sweetened it (the learning)."

Another discovery regarding the theme of learning journeyers was that participants in this study take MOOCs regularly, and a few had participated in the HumanMOOC multiple times. Julie said that the HumanMOOC helped her identify "what I look for, why I enjoy some courses and I stick with them until the end... reflect on why, or discover some of my motivation, where my motivation lies when it comes to humanizing." Additionally, learning from others in a culturally diverse MOOC and from a variety of professors is a benefit of participating in MOOCs. Julie stated: "I noticed that my motivation and engagement is affected by the style of the instructor, not just the design of the course, or not just the subject." She took two MOOCs on the same topic with similar content, but was more engaged in the HumanMOOC simply because she preferred the instructor's style and interaction. The reflections that all the participants shared during the interviews were candid and the challenges they faced, as well as their likes and frustrations, were shared as part of their skill development and overall learning.

It was evident that all interviewees had clear intentions and purposes for joining the HumanMOOC that went above and beyond simply earning badges or completing the course. These intentions were either directly linked to improving their practices in the classroom by developing 
new skills (technical and pedagogical) and strategies based on the content and activities they engaged with in the MOOC, or indirectly linked through the formation of a community and network of peers with other MOOC participants.

\section{I think I can}

Those interviewed described themselves as having a range of prior experiences and beliefs in their ability to use technology in their teaching. Each of the participants in this study described their participation in the MOOC as having increased their knowledge in some way. Jessica said:

I'd say I got confidence because I saw some things that you were doing.... How the course was set up that I could translate to our D2L [Desire2Learn] learning platform, but the concepts.... As I looked back on it, it was more of a boost to get some ideas and then some confidence that I can do this. I can engage people. Our program has tripled in size at least. I know it's working.

Nell described how the experiences from the course helped them better understand the importance of scaffolding and modeling, stating:

My biggest transformation, my thinking was that I've got to go a little slower than I thought with people, because I've got to give them things that they can have a really positive experience with to build up their confidence so that they will kind of take off with things.

Additionally, Nell stated:

I really understood that it's about who you're learning with, or, you know, and how people are engaging with each other that actually challenges you and makes your thinking bigger and makes you think about things in a different way than you have before. And that's sort of.... That was big part of the value that I got out of that course, because I did go outside of my comfort zone.

Those with prior experience using technology in their teaching found the opportunity to build on what they already knew through learning from the experiences of others and sharing ideas. Jessica explained that she has always liked different technologies and wanted to expand her horizons. Tim explained that the course

opened my eyes to a few others [i.e., other technologies], and even had me look at some other ones that we already used in a new light...there's that one technology, VoiceThread, which Webster does not have a license for. And that was something I always thought was cool, but I didn't really think that it was necessarily worth the extra cost.

Seeing the direct integration of different technologies was helpful to Eric. He recalled the use of the instructors giving feedback through video recording during the HumanMOOC, which was new to him. Instructors modeling the use of video feedback during the MOOC was helpful to his implementation in his current course and is something he continues to use.

Participants identified both personal and institutional barriers that got in the way of them implementing what they had learned in the MOOC. Participants mentioned a lack of opportunity within their own institutions to get advice, learn new teaching methodologies or find support to implement in practice what they had learned. Todd said: 
I haven't had much opportunity to practice any of it yet. At the time I was enrolled or about to enroll in the master's program in instructional technology and I intended to use a lot of the information I learned from your course and from what I'd experienced in ModPo but circumstances didn't allow me to follow through on completing that program so I still have a lot of that information locked up in my head and if the opportunity allows me to pursue that line of learning again in the future I intend to use those things.

Jessica identified institutional barriers and lack of support:

I didn't feel that there were a lot of people at the university or with even in our university system that knew much about online teaching and learning... we did not have, or there weren't tutorials that were good that I could just learn about what I was supposed to do.

\section{Bringing it back to the classroom}

While participants highlighted the sense of support and increased confidence that came from collaborative experiences in the MOOC as well as the wayfinders modeling technology in their teaching and practice opportunities that came from the experience, it was not easily integrated into their actual practices at times because of different barriers participants faced when attempting to implement strategies learned in the HumanMOOC. Matt expressed his frustration with his lack of implementation of the ideas he took away from the MOOC, saying "my frustration with my participation in your course, was that I thought, I should really start to implement these things. I had good intentions for a while to do that, but they slipped away."

Tim faced some institutional obstacles related to licensing new software:

I actually convinced my university to allow me to use Flipgrid for all of the discussion questions. For a while it was not even approved, but I had to keep pushing and showing them examples. I went to Flipgrid and got them to allow me to beta test it for 90 days or something. So, I even showed them how that would look and then I got permission to use it in the class.

Technological barriers existed for Eric who became frustrated with the video feedback recording tool in the Canvas speedgrader; he sought tech support on his campus to overcome this obstacle. While technological barriers can cause some to discard implementing a new approach, rather than give up, Eric found a workaround using Zoom to record his feedback for students instead.

When asked about how the course may have impacted their teaching practices in a positive way, several interviewees shared their lived experiences of implementing new pedagogical approaches and technologies. For some participants, like Holly, the gains were in how to think about who their students were. Holly said, "what I got out of that [course] was actually a way of thinking about who your learners are was much more... was where the change occurred for me, I think, in terms of my teaching." Missy said:

I think maybe the other piece that did have impact was building that social presence very early into the course so that there are relationships between the students themselves beyond their relationship with me and I think what I do differently now than I did before was structure groups and open spaces that kind of are conducive to building and engaging social presence. 
In the HumanMOOC, each participant was asked to engage on tools external to the LMS in whatever way made them most comfortable while allowing those who wished to engage in the open to do so. One way to participate in the open was to join live Google Hangouts where we also had live Twitter Chats running at the same time, which was facilitated by one or two of the wayfinders using the hashtag \#HumanMOOC to extend the discussion within the Google Hangout and reach a wider audience. Jessica was inspired by this approach and is now using Twitter in her teaching.

I have all my students...develop a Twitter account and all of my classes include some Twitter chats, and then learning about where else you can go to engage in other Twitter chats. Then we do, although when I run an online class we generally just, it's not that many people so we just use the chat feature there if somebody wants to ask another question. I did model that...I really liked [it], that was my first experience with Twitter as a Twitter chat thing.

The HumanMOOC wayfinders made every effort to model effective practice using each of the technologies presented. Eric described how this modeling of effective practices led to an impact on his program:

so that was something, I think that I really picked up from the time at HumanMOOC as I was in the middle of revamping that program. And I just thought okay, this is really significant to keep in there. And that isn't to say that we don't try other methods through the...[for] which we now use Canvas, through the Canvas classroom to engage with students and show a video and just discussion forums and stuff. But to continue that sort of live synchronous session was I think a significant part of what we continued as a result of the class.

Eight of our 10 interviewees mentioned they had not used video in their teaching before taking HumanMOOC, but afterward implemented it on their own in their online and blended teaching, whether by adding instructor videos to the course, adding video to the discussions, or providing voice and video feedback. Missy spoke of her experience producing instructor videos:

I balked at it first and then I just saw the power and potential of it. So no, that was not part of my course at all [before HumanMOOC]. And even now with the faceto-face course, I'll present those even before the students come to the classroom so they'll know who I am before they walk in the room. So, the power and potential of building that relationship, I think with the students, at an early point in the course I think is so critical.

Tim talked about his first time teaching using video and said that his course

exploded through the use of video where I was not expecting it to be as powerful as it was. But it really was, and I think largely because of the types of questions I was asking. But also just students had never been in an online class with using video in that way.

Amy teaches writing and has started encouraging her students to use SoundCloud to record their writings as podcasts in their own voice, so that the students can listen to what they wrote and correct their own work.

Several participants mentioned implementing voice and/or video feedback on assignments and they all felt that it had a positive impact on the student experience; however, some said they 
would intentionally ask students in the future to describe the way they used the feedback and how it made them feel compared with a grade or text-based feedback. Tim said that he began to provide video feedback on a couple of the assignments in his course, "And the reason that really helps in computer science and it really helped our department is because sometimes it's so difficult to explain where the error is or the problem is just via text in an email." While Tim felt this was a more effective method, the videos took time to produce and he didn't have a sense of how the students received them. Eric had the same experience; as he implemented the use of voice and video feedback, he didn't collect information from his students on their effectiveness and will work to do so in the future. Missy did obtain input from her students when she implemented video feedback in her teaching after the HumanMOOC and said "the feedback from the students was just phenomenal."

Missy also implemented Flipgrid after learning of it in the course. She said that the use of video discussions made it easier to see who was present in the discussions and added a layer of accountability that gets lost in text-based discussions. As an instructor she said that it allowed her to have a better understanding of "who they [her students] are and what their intentions or goals are for the course so I can support them in that learning."

\section{Discussion}

While participants in this study indicated different intentions for joining the MOOC (e.g., form connections, learn new e-learning techniques and best practices, exploring the LMS), they all stated that completing the MOOC was never their top priority. This is consistent with what is found in the literature as a number of researchers point out that, from MOOC participants' perspective, meaningful learning is not defined by time in a MOOC or completion, but rather by each participant's learning goals (Liyanagunawardena et al., 2014; Loizzo, Ertmer, Watson, \& Watson, 2017; Zheng et al., 2015).

One of the major themes that emerged in this study is the increase in participants' selfefficacy beliefs as a result of participating in the MOOC, which supported and encouraged change in participants' practice. Perceived self-efficacy was formally defined by Bandura (1997) as one's personal beliefs about his or her capabilities to organize and execute courses of action to attain designated goals. Thus, self-efficacy beliefs do not concern an individual's actual skills and abilities, but rather judgment about the skills and abilities each possess. According to Bandura' theory of self-efficacy (1977), there are a number of sources that can be highlighted in a learning environment to support and promote the development of self-efficacy. Of special relevance to the development of self-efficacy for learning in MOOCs based on the findings of this study are vicarious experience, or one's observation of a role model performing the task successfully, and verbal persuasion.

Modeling both in terms of course design, which was based on the CoI framework (Garrison et al., 2000) as well as facilitation and interactions within the HumanMOOC by the wayfinders was important to learners and to their reported and future implementation of different technology tools and best practices in course design. New insights into pedagogical practices as well as emerging technologies to support humanization of online learning were learned in the HumanMOOC. Modeling the use of these tools can support the integration of these tools for participants as it allows for them to explore tools from a learner's perspective. Modeling was a 
strong factor in this study and should stand as its own category and not just a source of selfefficacy.

Frequently, professional development experiences involve one-way information being pushed out to the participants, allowing no space for application, practice, or feedback. The opportunities in HumanMOOC to practice, and also receive feedback from peers and wayfinders on that practice, enabled learners to feel a sense of accomplishment and to get constructive feedback in a safe space. As Tim stated: "the HumanMOOC wasn't just information [at] all. It was, 'Hey, let's explore these things together.' And it felt like even the wayfinders were exploring them in some cases with us, which was neat." This finding is not unique to this study and other research in the area of technology integration have highlighted the role that a community appraoch to professional development plays in improving participants actual practices (Sullivan, Neu, \& Yang, 2018).

Those we interviewed approached their learning as illustrated in Figure 3. Their learning is a cyclical approach that is directed and affected by a representation of major themes within a learning cycle/journey: motivation, modeling, intention, challenges along the way which deepens the learning happening on that journey. The learning journeyers theme encompasses intentions and motivations for learning that started before joining the HumanMOOC. The I think I can theme builds on the learner's prior experience and the modeling by the facilitators increases self-efficacy beliefs. Bringing it back to the classroom happened after the HumanMOOC as learners implemented activities and technology tools into their classroom or course, which circles back to the journey that learners take to develop and refine skills for their professional informal learning.

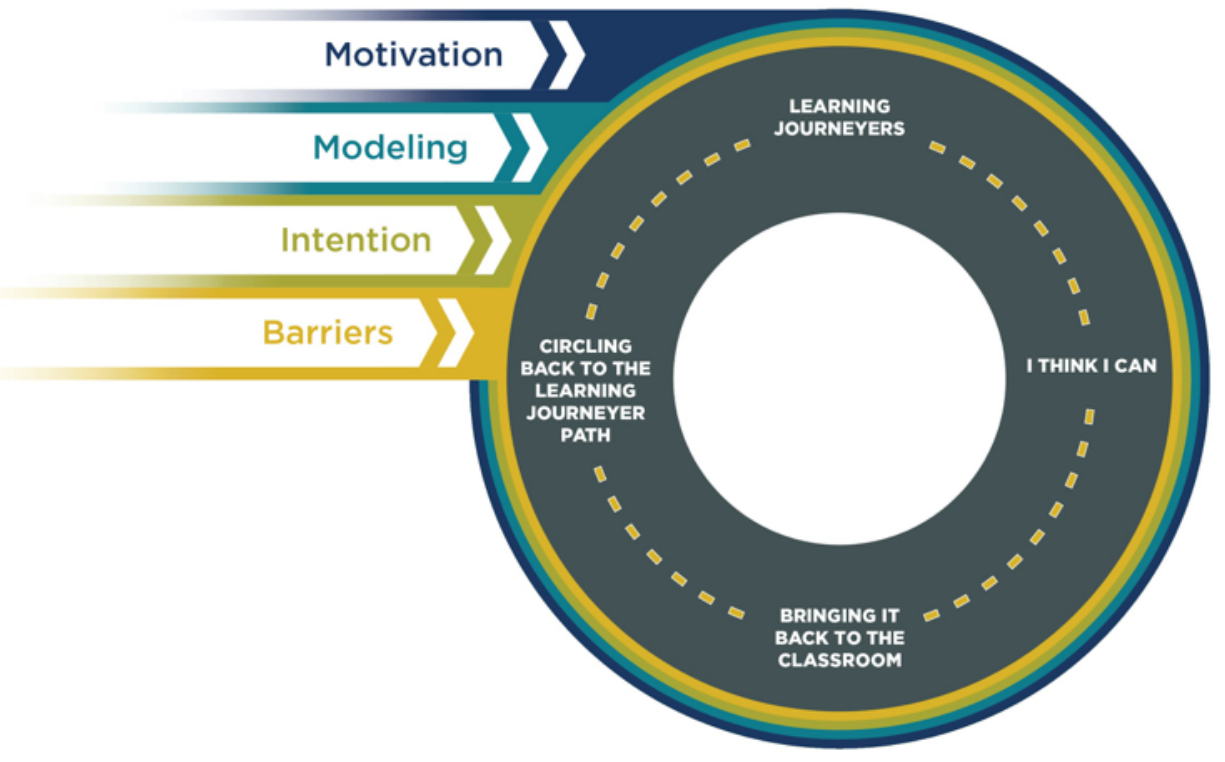

Figure 3. Factors influencing learning cycle in HumanMOOC.

The provision of ongoing, self-directed professional learning is a strategic goal for business, thus blurring the line even further between formal and informal learning (Deloitte Insights, 2017, 2018). The discussion needs to move away from "what is" to how we can integrate all available resources, whether formal or informal, to improve actual change in practice. Our hope 
is this study helps fill this gap by examining how faculty's participation in the HumanMOOC translated into actual change in practice. The findings can inform policymakers or learning and development units of how to strategically and effectively utilize informal and open resources for professional learning and development.

Given the informal, free, and flexible nature of MOOCs, participating in MOOCs was a result of a personal choice made by participants based on their individual and specific needs. However, implementing what was learned and experimenting with new ideas as a result of joining a MOOC can not be fully realized without institutional and pedagogical support. A number of participants shared their frustration with the lack of support as they try to integrate new technologies into their practices, indicating that at times the lack of integration into actual practices might not be so much related to MOOC design or personal factors, but rather contextual and organizational factors, an important issue to consider when using impact to practice as a measure of MOOC effectiveness.

\section{Conclusion}

The wider socioeconomic context in which higher education operates has not only provided new opportunities for professional development and learning, but has also redefined the meaning and basic assumptions we hold about work, development, knowledge, and learning (Eraut, 2011). In this new work context, individuals are not only encouraged, but expected to stay current in their field and abreast of new changes and developments because of the central role that personal learning plays in individual career development as well as overall institutional success and competitiveness (Gijbels et al., 2012; Manuti et al., 2015). As a result, interest in informal learning as a suitable context for in-time learning of complex and interdependent skills and knowledge needed to accomplish current and future job responsibilities has intensified. Despite the acknowledgement of the multiple pathways and forms in which professionals learn and the rising interest in informal professional learning, research in this area is still relatively limited especially within faculty professional learning literature (Gijbels et al., 2012; Macià \& García, 2016; Manuti et al., 2015; Tour, 2017).

This qualitative study has several potential limitations related to the sample interviewed and the data sources used. The findings of this study were based on data collected from previous HumanMOOC participants who have earned badges. Future research should also consider the experience of those who participated but did not earn badges and whether this factor plays a role, if any, in shaping their experience. In terms of the data sources in this study, the main source of data was the interviews conducted with participants. Triangulating and synthesizing findings from other data sources, such as observations and social media engagement, can provide a deeper understanding of MOOC learners' effort and experience in extending the learning that happens in MOOCs to their professional context. Despite these limitations, this study is significant in two main ways.

First, it adds to the literature on faculty informal learning, in the form of MOOCs, and what design and personal factors support participants' application of the new knowledge and skills to their professional context. Results of this study confirm what has been reported in previous studies (Milligan \& Littlejohn, 2014) and point to some of the contextual and technological barriers participants' face when trying to integrate new tools or enact new practices. However, based on the results of this study, there are some design and pedagogical strategies that has the potential of 
supporting faculty in mastering new knowledge and skills as well as in implementing the knowledge and skills gained in their actual practices. Results of this study show the need for more professional development opportunities that allow for application, practice, and feedback by nurturing a sense of community and encouraging connections and communications among learners. This approach not only enhances the learning effectiveness of MOOCs, but also allows learners to form personal learning networks that can serve as a support system that lasts beyond the boundaries of an individual MOOC. Additionally, strategies for overcoming some of the most common barriers to implementation can be included in MOOCs that target professional learners. For instance, MOOCs designers can provide opportunities for learners to plan ahead for such events by providing them with a space to discuss some of the anticipated challenges and share their experiences or plans in overcoming these barriers.

Second, this study pushes MOOC research forward by changing the narrative surrounding MOOC effectiveness from issues of course completion and certification to the impact of these courses on participants actual practices. Barriers to success within a MOOC has been investigated and examined in the literature (Loizzo, et al., 2017). However, for MOOCs to make an impact on practice, one must investigate the types of barriers most commonly reported by practitioners and professionals in the field. Understanding this allows MOOC designers and providers to pay explicit attention to these barriers in MOOCs and enhance participants chances of overcoming these hurdles by providing learners with evidence-based best practices as well as encouraging learners to discuss these issues and share experiences (Sullivan et al., 2018). Another interesting area for research is to understand how personal learning networks developed within a MOOC evolve over time and in what ways these networks provide support to members as they attempt to enact new strategies and practices. 
A Phenomenological Study of HumanMOOC Participants' Learning and Implementation into Practice

\section{References}

Bandura, A. (1977). Self-efficacy: Toward a unifying theory of behavioral change. Psychological Review, 84(2), 191-215. http://citeseerx.ist.psu.edu/viewdoc/download?doi=10.1.1.315.4567\&rep=rep1\&type=pdf

Beckingham, S., Nerantzi, C., Reed, P., \& Walker, D. (2015). Speedy professional conversations around learning and teaching in higher education via the brand new tweetchat\# LTHEchat. ALISS Quarterly. http://shura.shu.ac.uk/9337/

Boud, D., \& Hager, P. (2012). Re-thinking continuing professional development through changing metaphors and location in professional practices. Studies in Continuing Education, 34(1), 17-30. doi: 10.1080/0158037X.2011.608656

Brown, M. (2017). Trends and technologies: Teaching and learning. ECAR. https://library.educause.edu/resources/2017/5/2017-trends-and-technologies-teachingand-learning

Brown, M. (2018, January 25). Presenting the ELI key issues for 2018. EDUCAUSE Review. https://er.educause.edu/blogs/2018/1/presenting-the-eli-key-issues-for-2018

Castaño, C., Maiz, I., \& Garay, U. (2015). Design, motivation and performance in a cooperative MOOC course. Comunicar. Revista Cientí ca de Educación y Comunicación, 44, 19-26. http://eprints.rclis.org/24347/

Cook, M. (2016). State of the MOOC 2016: A year of massive landscape change for Massive Open Online Courses. Online Course Report. http://www.onlinecoursereport.com/stateof-the-mooc-2016-a-year-of-massive-landscape-change-for-massive-open-onlinecourses/

Dabbagh, N., \& Kitsantas, A. (2012). Personal learning environments, social media, and selfregulated learning: A natural formula for connecting formal and informal learning. The Internet and Higher Education, 15(1), 3-8.

Dall'Alba, G., \& Sandberg, J. (2006). Unveiling professional development: A critical review of stage models. Review of Educational Research, 76(3), 383-412. doi:

$10.3102 / 00346543076003383$

Daniel, J. (2012). Making sense of MOOCs: Musings in a maze of myth, paradox and possibility. Journal of Interactive Media in Education, 2012(3). doi: 10.5334/2012-18

Deloitte Insights. (2018). The rise of the social enterprise. 2018 global human capital trends report. https://www2.deloitte.com/insights/us/en/focus/human-capital-trends.html

Denzin, N. K., \& Lincoln, Y. S. (2005). Introduction: The discipline and practice of qualitative research. In N. K. Denzin \& Y. S. Lincoln (Eds.), The Sage handbook of qualitative research (pp. 1-32). Sage Publications.

Desimone, L. M. (2011). A primer on effective professional development. Phi Delta Kappan, 92(6), 68-71.

Eraut, M. (2000). Non-formal learning and tacit knowledge in professional work. British Journal of Educational Psychology, 70(1), 113-136. 
A Phenomenological Study of HumanMOOC Participants' Learning and Implementation into Practice

Eraut, M. (2011). Informal learning in the workplace: Evidence on the real value of work-based learning (WBL). Development and Learning in Organizations: An International Journal, 25(5), 8-12.

Fontana, R. P., Milligan, C., Littlejohn, A., \& Margaryan, A. (2015). Measuring self-regulated learning in the workplace. International Journal of Training and Development, 19(1), 32-52. doi: 10.1111/ijtd.12046

Garrison, D. R., Anderson, T., \& Archer, W. (2000). Critical inquiry in a text-based environment: computer conferencing in higher education. The Internet and Higher Education, 2(2-3), 87-105. doi: https://doi.org/10.1016/S1096-7516(00)00016-6

Gast, I., Schildkamp, K., \& van der Veen, J. T. (2017). Team-based professional development interventions in higher education: A systematic review. Review of Educational Research, 87(4), 736-767. doi: 10.3102/0034654317704306

Gijbels, D., Raemdonck, I., Vervecken, D., \& Van Herck, J. (2012). Understanding work-related learning: The case of ICT workers. Journal of Workplace Learning, 24(6), 416-429.

Jobe, W., Östlund, C., \& Svensson, L. (2014). MOOCs for professional teacher development. In Society for Information Technology \& Teacher Education International Conference (pp. 1580-1586). Association for the Advancement of Computing in Education (AACE).

Johnson, S. (2017, October 13). MIT moves beyond the MOOC to court companies, professional learners. Edusurge. https://www.edsurge.com/news/2017-10-13-mit-moves-beyond-themooc-to-court-companies-professionallearners?utm _content $=$ bufferefb $47 \& u t m \_$medium $=$social\&utm_source=twitter.com\&utm campaign $=$ buffer

Kelly, N., \& Antonio, A. (2016). Teacher peer support in social network sites. Teaching and Teacher Education, 56, 138-149.

Kennedy, A. (2014). Models of continuing professional development: A framework for analysis. Professional Development in Education, 40(3), 336-351. doi:

10.1080/19415257.2014.929293.

Kilgore, W. (2016). Design of informal online communities in education [Doctoral dissertation, University of North Texas]. University of North Texas Digital Library https://digital.library.unt.edu/ark:/67531/metadc862820/

Kilgore, W., \& Al-Freih, M. (2017). MOOCs as an innovative pedagogical design laboratory. International Journal on Innovations in Online Education, 1(1). doi: 10.1615/IntJInnovOnlineEdu.2016015210

Kilgore, W., \& Lowenthal, P. R. (2015). The human element MOOC. In R. D. Wright (Ed.), Student-teacher interaction in online learning environments (pp. 373-391). IGI Global.

Kukulska-Hulme, A. (2012). How should the higher education workforce adapt to advancements in technology for teaching and learning? The Internet and Higher Education, 15(4), 247254. 
A Phenomenological Study of HumanMOOC Participants' Learning and Implementation into Practice

Laurillard, D. (2016). The educational problem that MOOCs could solve: Professional development for teachers of disadvantaged students. Research in Learning Technology, 24, 29369. doi: 10.3402/rlt.v24.29369

Littlejohn, A., Hood, N., Milligan, C., \& Mustain, P. (2016). Learning in MOOCs: Motivations and self-regulated learning in MOOCs. The Internet and Higher Education, 29, 40-48. doi: 10.1016/j.iheduc.2015.12.003.

Littlejohn, A., \& Milligan, C. (2015). Designing MOOCs for professional learners: Tools and patterns to encourage self-regulated learning. eLearning Papers, 42(4).

Livingstone, D. W. (2001). Adults' informal learning: Definitions, findings, gaps and future research. Working Paper no. 21. New Approaches to Lifelong Learning.

Liyanagunawardena, T. R., Parslow, P., \& Williams, S. (2014). Dropout: MOOC participants' perspective. In U. Cress \& C. D. Kloos (Eds.), Proceedings of the European MOOC Stakeholder Summit 2014 (EMOOCs 2014) (pp. 95-100). Lausanne, Switzerland.

Loizzo, Jamie, Ertmer, Peggy A., Watson, William R., \& Watson, Sunnie Lee (2017). Adults as self-directed and determined to set and achieve personal learning goals in MOOCs: learners' perceptions of MOOC motivation, success, and completion. Online Learning, 21(2). doi: $10.24059 /$ olj.v21i2.889

Macià, M., \& García, I. (2016). Informal online communities and networks as a source of teacher professional development: A review. Teaching and Teacher Education, 55, 291-307.

Manuti, A., Pastore, S., Scardigno, A. F., Giancaspro, M. L., \& Morciano, D. (2015). Formal and informal learning in the workplace: A research review. International Journal of Training and Development, 19(1), 1-17. doi: 10.1111/ijtd.12044

McConnell-Henry, T., Chapman, Y., \& Francis, K. (2009). Husserl and Heidegger: Exploring the disparity. International Journal of Nursing Practice, 15(1), 7-15.

Milligan, C., \& Littlejohn, A. (2014). Supporting professional learning in a massive open online course. The International Review of Research in Open and Distributed Learning, 15(5). doi: 10.19173/irrodl.v15i5.1855

Moustakas, C. (1994). Phenomenological research methods. Sage Publications.

Nerantzi, C. (2015). Who says academics don't do CPD? Connecting practitioners and developing together through distributed cross-institutional collaborative CPD in the open. Journal of Perspectives in Applied Academic Practice, 3(1), 98-108.

O'Brien, J. (2018, May 7). The future of Educause, Part 3: Reimagined professional learning. Educause. https://er.educause.edu/articles/2018/5/the-future-of-educause-part-3reimagined-professionallearning?utm_source $=$ Informz\&utm_medium $=$ Email\&utm_campaign $=E R$

Olazabalaga, I. M., Garrido, C. C., \& Ruiz, U. G. (2016). Research on MOOCs: Trends and methodologies. Porta Linguarum, 87-98. http://www.ugr.es/ portalin/articulos/PL_monograph1_2016/art_7.pdf 
Purvis, A., Rodger, H., \& Beckingham, S. (2016). Engagement or distraction: The use of social media for learning in higher education. Student Engagement and Experience Journal, 5(1). doi: 10.7190/seej.v5.i1.104

Radford, A. W., Coningham, B., \& Horn, L. (2015). MOOCs: Not just for college studentsHow organizations can use MOOCs for professional development. Employment Relations Today, 41(4), 1-15. doi: 10.1002/ert.21469

Ravitch, S. M., \& Carl, N. M. (2015). Qualitative research: Bridging the conceptual, theoretical, and methodological. Sage Publications.

Saldaña, J. (2009). The coding manual for qualitative researchers. Sage Publications.

Schulz, M., \& Roßnagel, C. S. (2010). Informal workplace learning: An exploration of age differences in learning competence. Learning and Instruction, 20(5), 383-399.

Shah, D. (2016a). MOOC trends in 2016: MOOCs no longer massive. Class Central. https://www.class-central.com/report/moocs-2015-stats/

Shah, D. (2016b). Monetization over massiveness: Breaking down MOOCs by the numbers in 2016. EdSurge. https://www.edsurge.com/news/2016-12-29-monetization-overmassiveness-breaking-down-moocs-by-the-numbers-in-2016

Sneddon, J., Barlow, G., Bradley, S., Brink, A., Chandy, S. J., \& Nathwani, D. (2018). Development and impact of a massive open online course (MOOC) for antimicrobial stewardship. Journal of Antimicrobial Chemotherapy, 73(4), 1091-1097. doi:10.1093/jac/dkx493.

Stewart, C. (2014). Transforming professional development to professional learning. Journal of Adult Education, 43(1), 28-33.

Sullivan, R., Neu, V., \& Yang, F. (2018). Faculty development to promote effective instructional technology integration: A qualitative examination of reflections in an online community. Online Learning, 22(4), 341-359. doi: 10.24059/olj.v22i4.1373

Thacker, E. S. (2017). “PD is where teachers are learning!” High school social studies teachers' formal and informal professional learning. The Journal of Social Studies Research, 41(1), $37-52$.

Tour, E. (2017). Teachers' personal learning networks (PLNs): Exploring the nature of selfinitiated professional learning online. Literacy, 51(1), 11-18. 